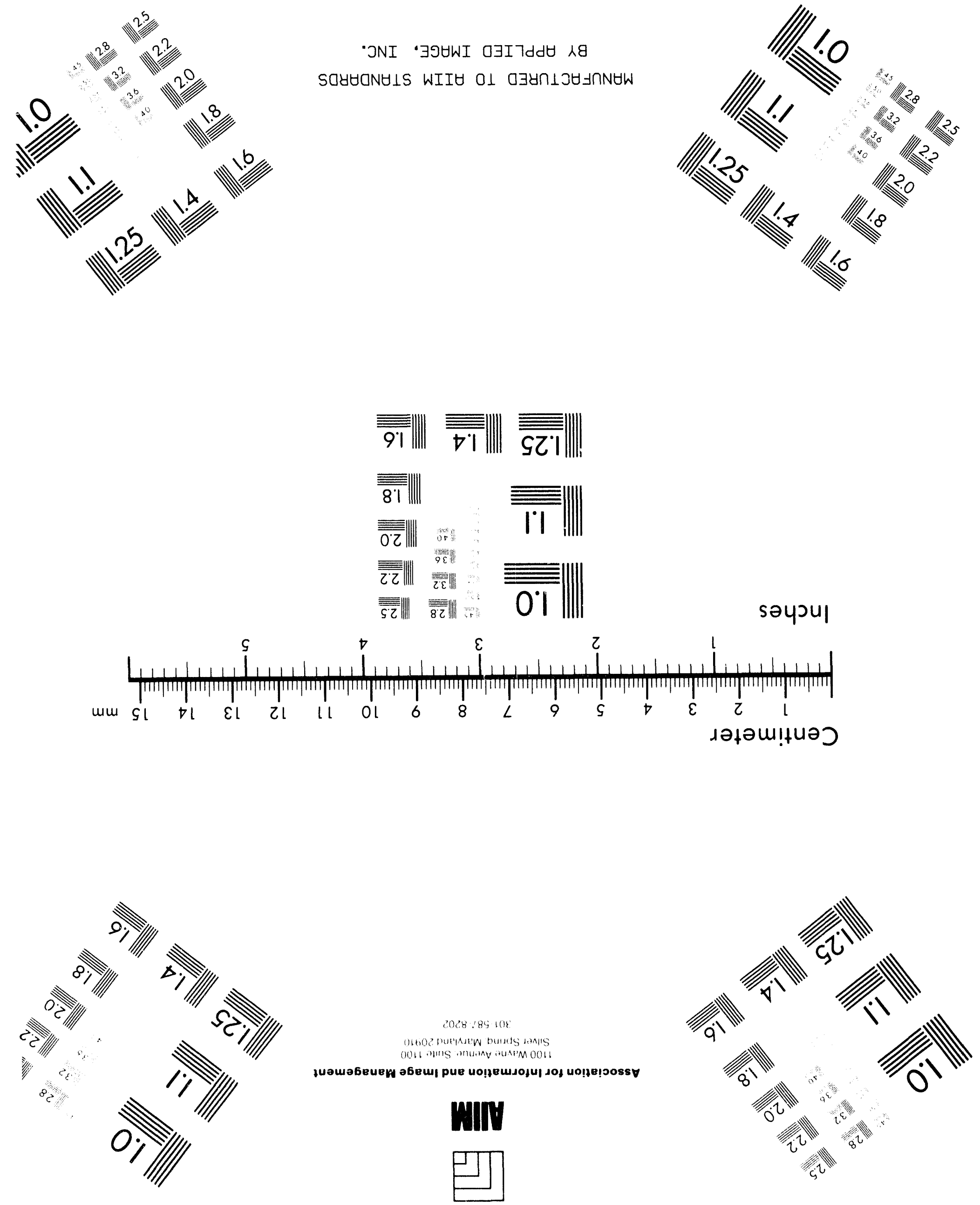



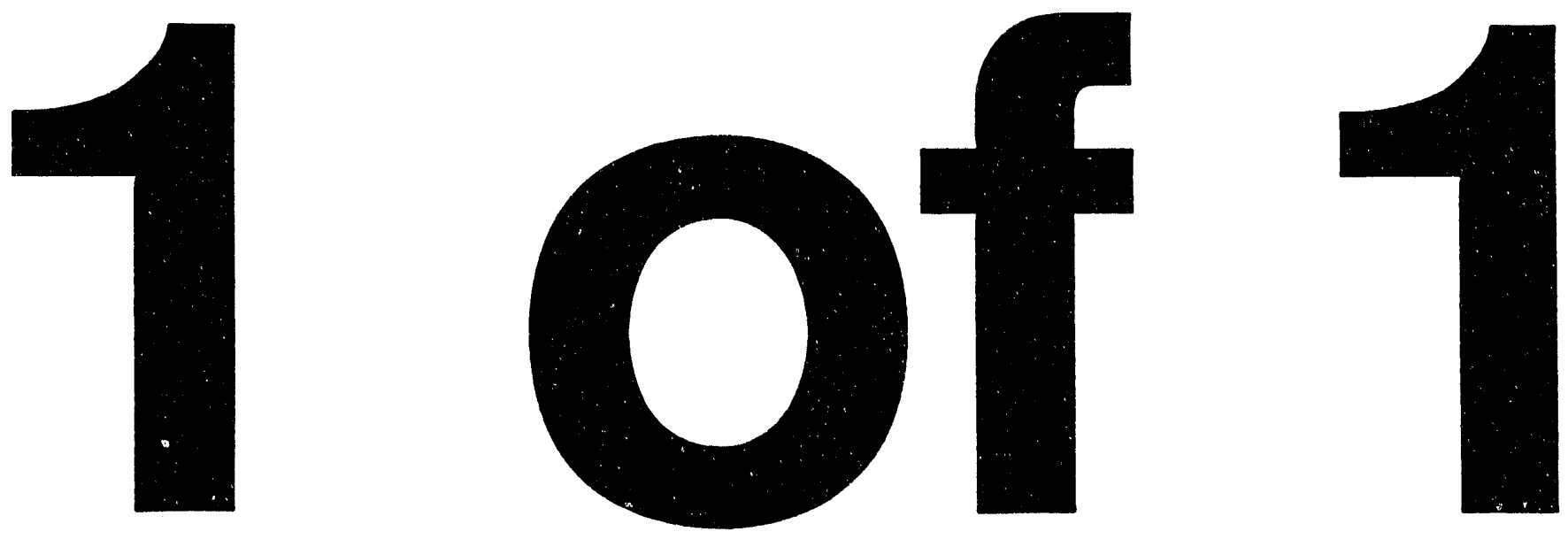
LA-UR- 94-1956

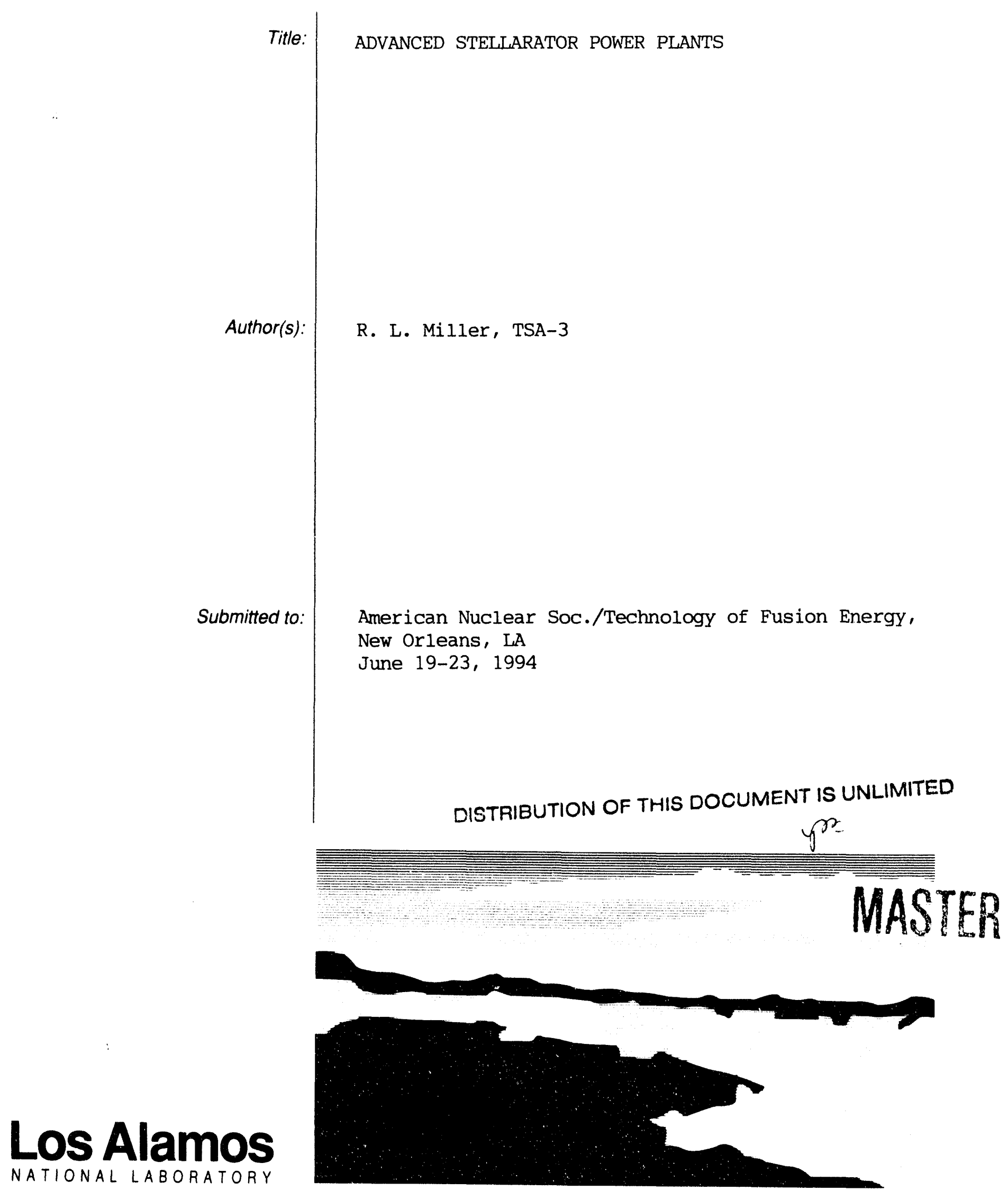

Los Alamos National Laboratory. an affirmative actioniequal opportunity emplóyer, is operated by the University of California for the U.S. Department of Energy under contract W-7405-ENG-36. By acceptance of this article. the publisher recognizes that the U.S. Government retains a nonexclusive, royalty-free license to publish or reproduce the published form of this contribution, or to allow others to do so, for U.S. Government purposes. The Los Alamos National Laboratory requests that the publisher identity this article as work performed under the auspices of the U.S. Department of Energy. 


\title{
ADVANCED STELLARATOR POWER PLANTS
}

\author{
Ronald L. Miller \\ Los Alamos National Laboratory \\ P.O. Box 1663 \\ Los Alamos, NM 87545 \\ (505)667-4950
}

\begin{abstract}
The stellarator is a class of helical/toroidal magnetic fusion devices. Recent international progress in stellarator power plant conceptual design is reviewed and comparisons in the areas of physics, engineering, and economics are made with recent tokamak design studies.
\end{abstract}

\section{INTRODUCTION}

\section{A. Background}

The term "stellarator" (inclusive of torsatron and heliotron configurations) refers to a class of helical/toroidal magnetic fusion devices that produces confinining magnetic fields by currents in external coils only ${ }^{1}$. Relative to the tokamak, the stellarator promises disruption-free, steady-state operation with reduced recirculating power due to the absence of current-drive requirements. Such advantages may be offset by more complicated coil, blanket/shield, and divertor (i.e., impurity control) configurations. The fundamental stellarator configuration and the anticipated higher plasma aspect ratio, $A \equiv R_{T} / a_{p} \simeq 8$, relative to the tokamak also result in different overall performance as monitored by the usual figures of merit (e.g., power density, stored magnetic energy, peak coil magnetic field strength, neutron wall load, and projected cost of electricity, COE). Considerable international progress has been made in the conceptual design of stellarator power plants in the last decade since a prior review in this forum ${ }^{2}$; recent progress is reviewed here. The future payoff of the stellarator approach is a possible post-ITER ${ }^{3,4}$ candidate for an attractive demonstration (DEMO) ${ }^{5}$ and subsequent DT-fueled commercial power plant with attractive features relative to the tokamak.

\section{B. Theoretical/Experimental Basis}

Recent reviews of the theoretical and experimental background of world stellarator research are available elsewhere $e^{6,7,8,9}$. Nearly a dozen experimental devices at ten institutes are in operation, with several others under construction or proposed, making the stellarator the most vigorous non-tokamak approach to magnetic fusion energy (MFE). The maximum plasma temperatures in present stellarators are comparable to the values obtained in medium-sized tokamaks (a few keV) and beta values are a few percent. Stellarator plasma energy confinement is seen to improve with density, magnetic-field strength, and volume, but degrades with input power; enhanced (H-mode) confinement has been observed in two devices. The global ( $\mathrm{L}$-mode) energy confinement time, $\tau_{E}$, is given by (for example) the Lackner-Gottardi relation $^{10,11}$

$$
\tau_{E}^{L-G}=0.17 R_{T} a_{p}^{2} \bar{n}^{0.6} B_{0}^{0.8} P^{-0.6} t^{0.4},
$$

where $R_{T}(\mathrm{~m})$ is the major toroidal radius, $a_{p}(\mathrm{~m})$ is the average plasma minor radius, $\bar{n}\left(10^{20} \mathrm{~m}^{-3}\right)$ is the line-averaged plasma density, $B_{0}(\mathrm{~T})$ is the on-axis magnetic-field strength, $P(\mathrm{MW})$ is the heating power, and $t$ is the rotational transform (i.e., the inverse of the tokamak safety factor, $q$ ). A possible enhancement factor, $H$, relative to Eq. (1) is monitored (i.e., $H \simeq 2$ for $\mathrm{H}$ mode). Operation is disruption-free and without vertical displacement events; feedback control of the plasma position is not required. The magnetic-field topology in the edge-plasma region typically provides a natural divertor configuration. 
Approaches have been developed to reduce the plasma aspect ratio, $A$, in torsatrons ${ }^{12,13}$. Onedimensional transport analysis with self-consistent radial electric fields yields encouraging results ${ }^{14}$, suggesting viable operating regimes even with large fusion-product $\alpha$-particle loss. A continuous helicalcoil machine, the Large Helical Device (LHD), is now under construction in Japan ${ }^{15}$. After an 18 . month downtime, the U.S. Advanced Toroidal Facility (ATF) ${ }^{16}$ torsatron at ORNL is expected to be "mothballed" soon because of a lack of operating funds ${ }^{17}$.

The helical-axis advanced stellarator (helias) $)^{18,19}$ is being developed to raise beta limits, reduce neoclassical transport, and improve the confinement of $\alpha$-particles. A modular-coil design with five field periods, Wendelstein 7-X, is being proposed in Germany ${ }^{20}$. A small $(R=1.2 \mathrm{~m}$ ) four-field-period Helically Symmetric Toroidal Experiment (HSX) is under construction at the University of Wisconsin ${ }^{21}$.

\section{Reactor Studies}

A cluster of stellarator conceptual reactor design studies was performed about a dozen years ago ${ }^{2}$ for both continuous-helical-coil and modular (nonplanar) configurations. Several studies ${ }^{22,23}$ in the interim have set the stage for the recent/on-going work summarized here. Work on the Force Free Helical Reactor (FFHR) ${ }^{24}$ conceptual design in Japan is connected to the LHD project. The Helias Stellarator Reactor (HSR) ${ }^{19,20,25}$ is under investigation in Germany in conjunction with the W7-X proposal. The multi-institutional U.S. Stellarator Power Plant Study (SPPS) ${ }^{26}$ has been initiated recently to assess, using the latest theoretical and experimental information, the commercial potential of the stellarator class. To focus the effort, the reference SPPS configuration has been selected to be a Modular Heliaslike Heliac (MHH), in preference to a torsatron ${ }^{27}$. Where appropriate, assumptions, models, and (lowactivation) materials choices in common with the recent ARIES $^{28}$ tokamak power-plant studies are employed in the SPPS to facilitate meaningful comparisons. As tokamak reactor design studies ${ }^{28,29}$ seek to invoke the advantages of steady-state operation, current-drive requirements dictate delicate plasma profile control to enhance larger bootstrap-current fractions as well as reduced beta values and other offoptimal choices, perhaps opening a window of competitive opportunity for the stellarator approach to MFE.

\section{RESULTS}

Results from the several ongoing DT-fueled stellarator power-plant design studies are summmarized in Table I. These results are incomplete and preliminary, reflecting the ongoing status of these studies. Cost projections are not available for either the FFHR or the HSR. One of the groundrules of the HSR study is the use of NbTi coil technology. The HSR is also based on conservative L-mode energy confinement. If not ignited or thermally stable in the strict sense, a small amount of $\mathrm{rf}$ heating power might be used for control purposes in the stellarators. Each stellarator is typically larger and has lower system power density and first-wall (average) $14.1-\mathrm{MeV}$ neutron wall loading than the ARIES-IV tokamak. Projected stellarator beta values are higher than for the ARIES tokamaks, resulting in lower magnetic fields at the coils, which result may be appropriate for the nonplanar HSR and MHH coils. Details of the various divertor systems are not yet available.

\section{SPPS}

The SPPS, to be completed in late 1994, integrates physics, engineering, and systems studies to identify potentially attractive stellarator design points. The multi-institutional SPPS team includes a subset of the ARIES/PULSAR team augmented by U.S. and other stellarator experts. The reference SPPS coil configuration, selected to maximize the physics performance of the non-planar-axis deuterium-tritium plasma (e.g., favorable transport, efficient fusion-product heating, $\beta \simeq 0.05$, etc.), is illustrated in Fig. 1. For a commercial power plant, the major toroidal "radius" would be $R_{T} \simeq 14 \mathrm{~m}$. Studies are in progress to explore reduced fusion power core (FPC) sizes and costs. There are eight non-planar superconducting coils per field period of four distinct types, appropriate for off-site factory fabrication. No additional set of vertical-field coils is required. Peak coil magnetic-field strength is expected to be less than for a tokamak of comparable power output in the range 1-2 GWe. The peak coil fields are developed near the four inboard "corners" apparent in Fig. 1.

A critical design constraint is the desire to minimize the standoff between the inboard plasma edge and the coil winding pack consistent with adequate tritium breeding in the lithium-bearing blanket and sufficient neutronic shielding of the coils. The coolant/structure combination of $\mathrm{Li} / \mathrm{V}$-alloy used in ARIES-II ${ }^{28}$ may introduce unacceptable MHD field errors in stellarators. The initial choice of a $\mathrm{He}$ cooled, SiC-composite-structure, solid breeder ( $\mathrm{Li}, \mathrm{O})$ is made for the MHH, in common with ARIES-IV. 
TABLE I. Summary of 1-GWe Stellarator Power-Plant Designs and ARIES-IV Tokamak ${ }^{(a)}$

\begin{tabular}{|c|c|c|c|c|}
\hline Parameter & FFHR & HSR & $\mathrm{MHH}$ & $\mathrm{A}-\mathrm{IV}^{(a)}$ \\
\hline \multicolumn{5}{|l|}{ GEOMETRY } \\
\hline Major radius, $R_{T}(\mathbf{m})$ & 20. & 19.5 & 14.0 & 6.04 \\
\hline Minor radius, $a_{p}(\mathrm{~m})$ & 2.0 & 1.59 & 1.63 & 1.51 \\
\hline Vertical elongation, $\kappa$ & & $\sim 2.5$ & 2.6 & 2.03 \\
\hline Aspect ratio, $A=R_{T} / a_{p}$ & 10 & 12.2 & 8.6 & 4.0 \\
\hline \multicolumn{5}{|l|}{ PHYSICS } \\
\hline Number of field periods 5 & 4 & NA & & \\
\hline Plasma beta, $\beta(\%)$ & $0.7-4.5$ & 5.0 & 5.0 & 3.4 \\
\hline Temperature, $T_{i}(\mathrm{keV})$ & $\sim 10$ & 9 & 10 & 10 \\
\hline Density, $n_{e}\left(10^{20} / \mathrm{m}^{3}\right)$ & 1.3 & 1.3 & 1.5 & 2.9 \\
\hline Confinement factor, $H$ & & $\sim 1$ & 2.2 & 3.1 \\
\hline Radiation fraction, $f_{R A D}$ & & & 0.23 & 0.23 \\
\hline Plasma current, $I_{\phi}(\mathrm{MA})$ & 0. & 0. & 0. & 6.64 \\
\hline Bootstrap fraction, $f_{B C}$ & NA & NA & NA & 0.87 \\
\hline Gain, $Q_{p}=P_{F} / P_{C D}$ & $\infty$ & $\infty$ & $\infty$ & 29.8 \\
\hline \multicolumn{5}{|l|}{ BLANKET/SHIELD } \\
\hline Coolant & Flibe & $\mathrm{Li}$ & $\mathrm{He}$ & $\mathrm{He}$ \\
\hline Structure & $J L F-1^{b}$ & & $\mathrm{SiC}$ & $\mathrm{SiC}$ \\
\hline Tritium breeder & Flibe & & $\mathrm{Li}_{2} \mathrm{O}$ & $\mathrm{Li}_{2} \mathrm{O}$ \\
\hline Neutron multiplier & & & $\mathrm{Be}$ & \\
\hline Shield & $\mathrm{B}_{4} \mathrm{C}$ & & $\mathrm{SiC}$ & $\mathrm{SiC}$ \\
\hline \multicolumn{5}{|l|}{ MAGNETS } \\
\hline On-axis field, $B_{0}(\mathrm{~T})$ & & 5.0 & 5.3 & 7.6 \\
\hline Conductor & $\mathrm{Nb}_{3} \mathrm{Sn}$ & $\mathrm{NbTi}$ & $\mathrm{Nb}_{3} \mathrm{Sn}$ & $\mathrm{Nb}_{3} \mathrm{Sn}$ \\
\hline TF-coil peak field, $B_{\phi c}(\mathrm{~T})$ & $14-9$ & 10.7 & 11.5 & 15.9 \\
\hline Magnetic energy, $W_{B}$ (GJ) & 1290 & 70 & TBD & 93 \\
\hline \multicolumn{5}{|l|}{ Specific energy } \\
\hline$W_{B} / M_{c}(\mathrm{MJ} / \mathbf{k g})$ & & & TBD & 34 \\
\hline \multicolumn{5}{|l|}{ REACTOR PERFORMANCE } \\
\hline Thermal efficiency, $\eta_{T H}$ & & 0.35 & 0.49 & 0.49 \\
\hline Engr. gain, ${ }^{(c)} Q_{E}=\epsilon^{-1}$ & & 11.1 & 10.9 & 5.20 \\
\hline Wall loading, $I_{w}\left(\mathrm{MW} / \mathrm{m}^{2}\right)$ & & 1.0 & 1.2 & 2.67 \\
\hline $\begin{array}{l}\text { Mass Power Density, MPD }= \\
P_{E} / M_{F P C}(\mathrm{kWe} / \text { tonne })\end{array}$ & TBD & 42 & 73 & 111 \\
\hline Level of Safety & & & & \\
\hline Assurance, $\operatorname{LSA}^{(d)}$ & NA & NA & 1 & \\
\hline \multicolumn{5}{|l|}{ COSTS (Constant-1992 \$) } \\
\hline Unit Tbtal Cost, UTC (\$/We) & & & 4.65 & 3.67 \\
\hline COE (millkWeh) w/o LSA & & & 106 & 90 \\
\hline COE (millkWeh) w/ LSA & & & 81 & 68 \\
\hline capital return & & & 68 & 53 \\
\hline O\&M & & & 8 & \\
\hline blanket replacement & & & 6 & \\
\hline decommissioning & & & 0.25 & 0.25 \\
\hline fuel & & & 0.03 & 0.03 \\
\hline \multicolumn{5}{|c|}{ (a) Second-Stability-Regime (SSR) ARIES-IV 28,30} \\
\hline \multicolumn{5}{|c|}{$\begin{array}{l}\text { (b) low-activation steel } \\
\text { (c) } \epsilon=P_{c} / P_{E T} \text {, fraction gross electric power rec }\end{array}$} \\
\hline (c) $\epsilon=P_{c} / P_{E T}$, fraction & 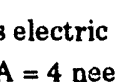 & & & \\
\hline
\end{tabular}

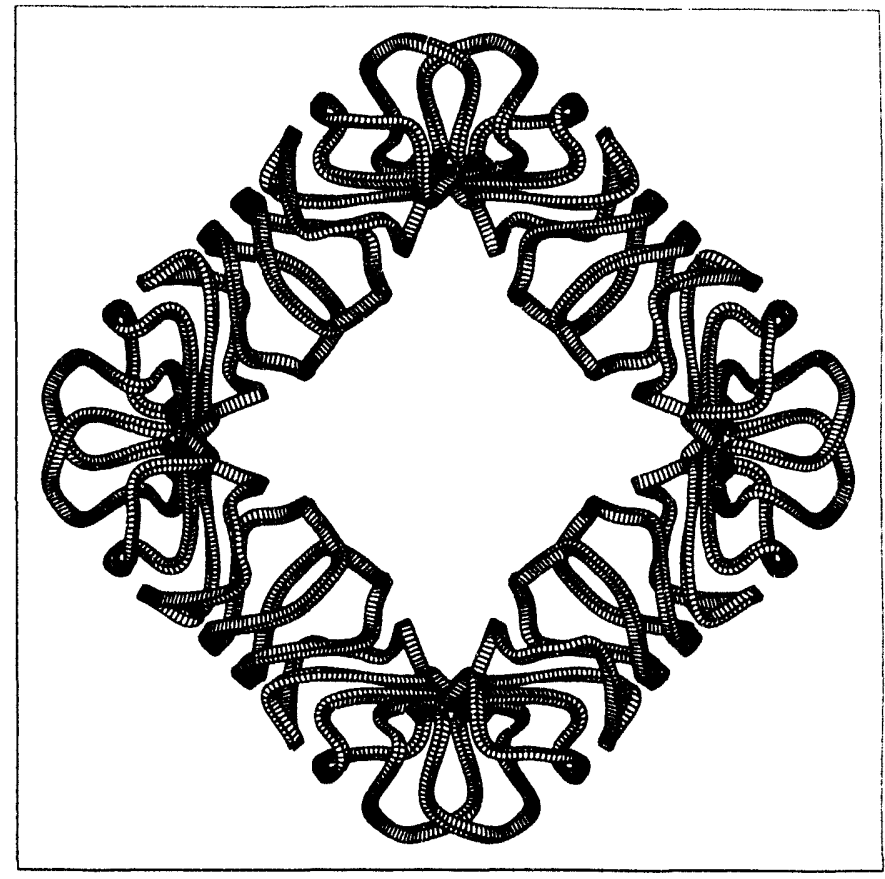

Fig. 1. Plan view of the four-field-period stellarator modular-coil configuration being used as a reference case by the U.S. Stellarator Power Plant Study. Typical major toroidal radius is $R_{T} \simeq 14 \mathrm{~m}$. (courtesy of D. T. Anderson and P. R. Garabedian).

Two systems codes are being applied in the SPPS study. The first is a modified form of the ARIES Systems Code (ASC) ${ }^{28}$, which uses a $0-D$, profile-averaged plasma model. The second code, TOROPT ${ }^{22,26}$, can be used as a platform for 1-D plasma studies as well as multi-variate optimizations. Both codes incorporate integrated physics, engineering, and costing models to identify potentially attractive stellarator design points. Typically, the projected cost of electricity $(\mathrm{COE}, \mathrm{mill} / \mathrm{kWeh})$ is used as a object function to be minimized. The cost model used in TOROPT has been coordinated with that used in ASC. Baseline assumptions, common to the ARIES tokamaks, include standard financial values, learning-curve cost credits for the FPC consistent with a 10th-of-a-kind plant, a six-year construction lead time, and a plant capacity factor, $p_{f} \simeq 0.76$. The cost scalings used for the powerplant balance of plant (BOP) are consistent with U.S. fission nuclear-reactor experience ${ }^{31}$. Credits for appropriate Levels of Safety Assurance (LSA) ${ }^{28,32}$ are included. The LSA scale varies from 4 to 1 , with LSA = 4 implying active engineered safeguards, as in present fission plants, and LSA $=1$ implying inherent, passive safety.

As the SPPS design proceeds, a more detailed analysis of reliability, availability, and maintenance 
(RAM) issues may provide a cost-related discriminator between tokamak and stellarator approaches. The relatively larger engineered volumes of the stellarator with longer pipe runs and weldments may be anticipated to experience more frequent random failures, while at the same time, the lower neutron wall loadings for the same assumed neutron fluence lifetime may result in shorter scheduled outages to replace FPC first-wall/blanket sectors. The helical character of the stellarator configuration complicates its engineering design; details of the conceptual engineering design are under development. AS seen in Fig. 1, there are a number of large openings in the coil set for access to the underlying shield/blanket/divertor systems. Stellarator-specific (remote) maintenance approaches may influence projected power-plant availability and O\&M costs. These RAM features require more detailed examination in the course of the SPPS.

\section{CONCLUSIONS}

Recent progress in the conceptual design of stellarator MFE power plants is encouraging. Recirculating power is low because of the absence of a currentdrive requirement, as for tokamaks. Mass power density is lower because of the requirement for nominal stand-offs at higher plasma aspect ratio. Higher beta values than seen in recent tokamak studies results in lower coil fields and stresses. The engineering configuration is complicated by the helical geometry. Solutions to the divertor and maintenance issues are not yet in hand.

\section{ACKNOWLEDGEMENTS}

This work was supported by the U.S. Department of Energy, Office of Fusion Energy, under Contract No. W-7405-ENG-36. Useful discussions and other cooperation involving C. G. Bathke (LANL), R. A. Krakowski (LANL), J. F. Lyon (ORNL), J. A. Rome (ORNL), F. Najmabadi (UCLA), L. A. El-Guebaly (U. Wisconsin), I. N. Sviatoslavsky (U. Wiscunsin), D. T. Anderson (U. Wisconsin), P. R. Garabedian (NYU), A. Sagara (NIFS), and G. Grieger (IPP-Garching) are gratefully acknowledged.

\section{REFERENCES}

1. L. Spitzer, "A Proposed Stellarator," Project Matterhorn report PM-S-1 (NYO-993) (July 1951).

2. R. L. Miller, "Recent Progress in Stellarator Reactor Conceptual Design," Fus. Techn., 8, 1, Part 2(B) (July 1985) 1581.

3. R. Parker, "Overview of the ITER EDA Design," (these proceedings).
4. W. M Stacey, "Extrapolation of ITER to DEMO and Commercial Reactors," (these proceedings).

5. R. W. Conn, et al., "The Requirements of a Fusion Demonstration Reactor and the STARLITE Study," University of California, Los Angeles report UCLA-PPG-1394 (February 1992).

6. B. A. Carreras, et al., "Progress in Stellarator/Heliotron Research: 1981-1986," Nucl. Fu.s., 28, 9 (1988) 1613.

7. J. F. Lyon, "Near-Term Directions in the World Stellarator Program," Fus. Techn., 17, 1, (January 1990) 17.

8. J. F. Lyon, "Review of Recent Stellarator Results in the U.S.A., the U.S.S.R., and Japan," Plasma Phys. and Contr. Fus., 32, 11 (1990) 1041.

9. F. Rau, "Report on the Ninth International Workshop on Stellarators," Nucl. Fus., 34, 2 (1994) 301.

10. K. Lackner and N. A. O. Gottardi, "Tokamak Confinement in Relation to Plateau Scaling," Nucl. Fus., 30, 4 (1990) 767.

11. A. Weller, ei al., "Optimum Confinement in the Wendelstein 7-AS Stellarator," Plasma Phys. and Contr. Fus., 33, 13 (1991) 1559.

12. B. Carreras, et al., "Low-Aspect-Ratio Torsatron Configurations," Nucl. Fus., 28, 7 (1988) 1195.

13. J. F. Lyon, et al., "Advanced Toroidal Facility II Studies," Fus. Technol. 17, 1 (January 1990) 188.

14. S. L. Painter and J. F. Lyon, "Transport Analysis of Stellarator Reactors," Nucl. Fus., 31, 12 (1991) 2271.

15. A. Iiyoshi et al., "Design Study for the Large Helical Device," Fus. Technol. 17, 169 (January 1991).

16. J. F. Lyon et al., "Construction and Initial Operation of the Advanced Toroidal Facility," Fus. Technol. 17, 1 (January 1991) 33.

17. J. A. Rome, "ATF Resumes Operation," Stellarator News, Issue \#3 (May 1994) p. 2.

18. J. Nürenberg and R. Zille, "Quasi-Helically Symmetric Toroidal Stellarators" Phys. Letters A, 129, 2 (9 May 1988) 113.

19. G. Greiger, et al., "Physics Optimization of Stellarators" Phys. Fluids B, 4, 7 (July 1992) 2081.

20. G. Grieger et al., "Modular Stellarator Reactors and Plans for Wendelstein 7-X," Fus. Technol. 21, 1767 (May 1992).

21. D. T. Anderson, U. Wisconsin, personal communication (1994).

22. J. F. Lyon and S. L. Painter, "Assessment of Torsatrons as Reactors," Oak Ridge National Laboratory report ORNL/TM-12189 (December 1992). 
23. G. Böhme, et al., "Studies of a Modular Advanced Stellarator Reactor ASRA6C," Fusion Power Associates report FPA-87-2 (May 1987).

24. Proceedings of the U.S.-Japan Workshop on Power Reactor Studies (Q-185)," University of California, Los Angeles report UCLA-PPG-1512 (March 1994).

25. C. Beidler, et al., "Reactor Studies of Advanced Stellarators," Proc. Fourteenth IAEA Conf. on Phys. and Contr. Nucl. Fus. Res., Würzburg, Germany (1992) (to be published).

26. J. F. Lyon, K. Gulec, R. L. Miller, and L. El-Guebaly, "Status of the U. S. Stellarator Reactor Study," Proc. IAEA Technical Committee Meeting and Workshop on Fusion Design and Technology V, UCLA (September 13-17, 1993) (Proceedings to be published).

27. J. F. Lyon, K Gulec, R. L. Miller, and L. El-Guebaly, "Evolution of Torsatrons as Reactors," Oak Ridge National Laboratory report ORNL/TM-12670 (March 1994).

28. F. Najmabadi, et al., "The ARIES-II and -IV Second Stability Tokamak Reactors," University of California, Los Angles report UCLA-PPG-1461 (to be published).

29. C. G. Bathke, "A Comparison of Steady-State ARIES and Pulsed PULSAR Tokamak Power Plants," (these proceedings).

30. R. A. Krakowski, et al., "Lessons Learned from the Tokamak Advanced Innovation and Evaluation Study (ARIES)," (these proceedings).

31. J. G. Delene, "Updated Comparison of Economics of Fusion Reactors with Advanced Fission Reactors," Fus. Technol. 19, 807 (May 1991).

32. J. P. Holdren et al., "Report of the Senior Committee on Environmental, Safety, and Economic Aspects of Magnetic Fusion Energy," Law ence Livermore National Laboratory report UCRL-53766 (1989).

\section{DISCLAIMER}

This report was prepared as an account of work sponsored by an agency of the United States Government. Neither the United States Government nor any agency thereof, nor any of their employees, makes any warranty, express or implied, or assumes any legal liability or responsibility for the accuracy, completeness, or usefulness of any information, apparatus, product, or process disclosed, or represents that its use would not infringe privately owned rights. Reference herein to any specific commercial product, process, or service by trade name, trademark, manufacturer, or otherwise does not necessarily constitute or imply its endorsement, recommendation, or favoring by the United States Government or any agency thereof. The views mend opinions of authors expressed herein do not necessarily state or reflect those of the United States Government or any agency thereof. 

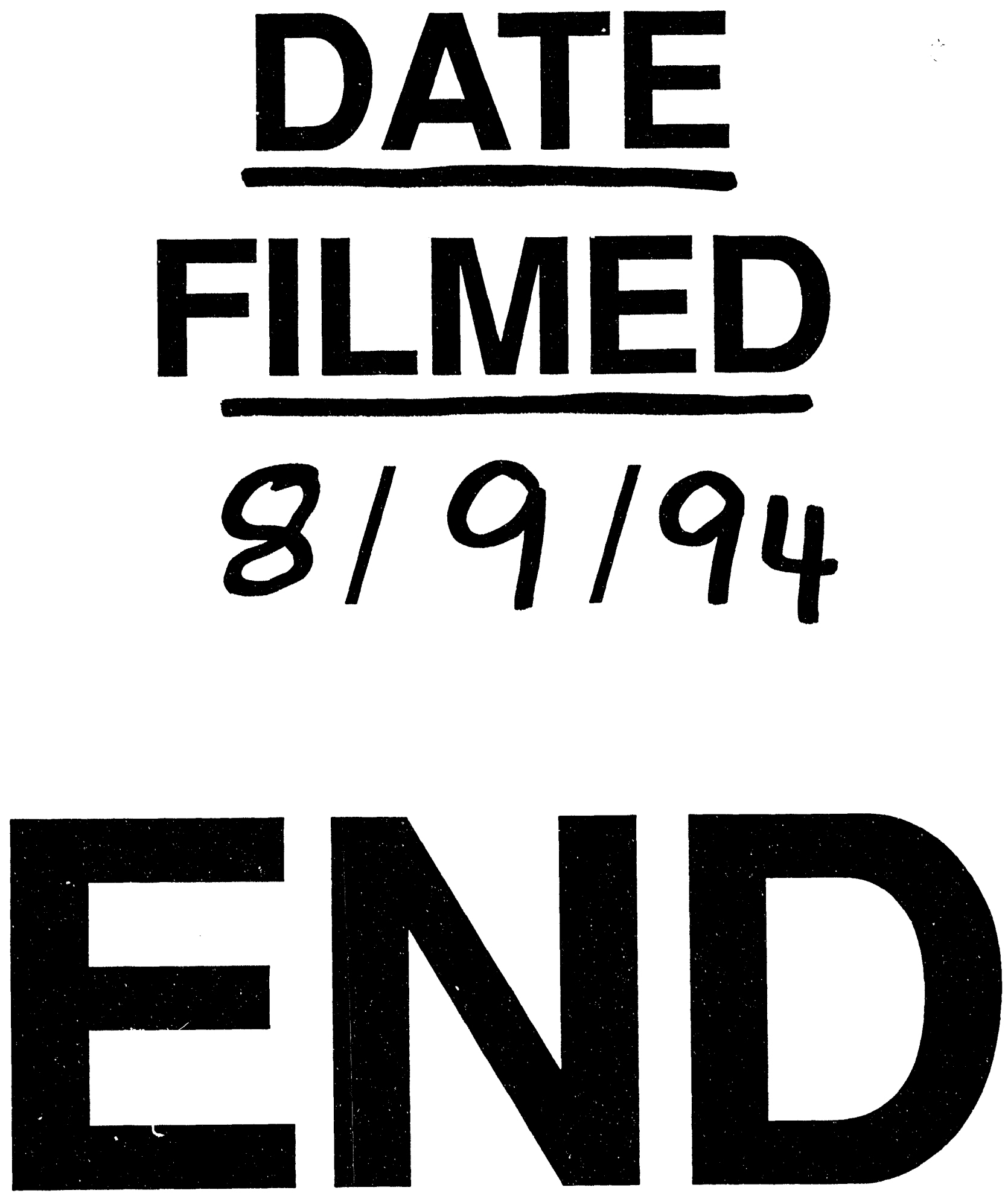
